https://www.journal-imab-bg.org

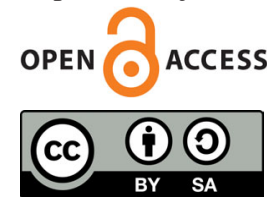

Original article

\title{
SOCIOECONOMIC CHARACTERISTICS OF COUNTRIES BASED ON THE PRESENCE OF HTA AGENCY
}

\author{
Svetlin Georgiev ${ }^{1}$, Antoniya Yanakieva ${ }^{1}$, Stamatios Priftis ${ }^{2}$ \\ 1) Department of Health Technology Assessment, Faculty of Public Health, \\ Medical University - Sofia \\ 2) Student, Faculty of Public Health, Medical University - Sofia, Bulgaria
}

\begin{abstract}
Background: Broadly defined, health technology assessment (HTA) is the systematic evaluation of medical technologies. This approach takes in to account effectiveness of the technologies, social and ethical aspects and efficiency as well as. A large number of countries globally have not yet implemented the use of HTA because of varying reasons.

Purpose: The study aims to show the correlation between the presence of official HTA body and the socioeconomic features.

Material/Methods: In a 3-month period we used the method of document analysis from different sources regarding the presence of HTA bodies all over the world. A process for verification of the information used was developed and implemented. The same process was used to derive the presented information from the analysis.

Results: About one in two countries have formal HTA process to inform decision making, in which they systematically collect data and consider the impacts of a particular health technology or intervention. However, almost à quarter of the studied countries are located in Europe, most of them $(86 \%)$ have an official HTA agency that operates in the country. We found that $80 \%$ of HTA bodies all over the World are located in countries with high income rate and most of them are European.

Conclusions It was found that it is possible to establish a correlation between the socio-economic parameters of a country and the existence of an active HTA agency in it.
\end{abstract}

Keywords: HTA, Agency, Socioeconomic, globally

\section{INTRODUCTION}

Health technology assessment is defined as "the systematic evaluation of properties, effects, and/or impacts of health technology. It may address the direct, intended consequences of technologies as well as their indirect, unintended consequences" [1]. Its main purpose is to provide well organized, evidence-based input to policy-making. This is necessary in order to help formulate effective health policies that are patient-focused and seek to achieve best the value. HTA shouldin one hand be firmly rooted in research and the scientific method and on the other hand to be balanced between all evidence. The use of high-quality evidence for policy and managerial decision-making can be a challenge due to the relationships between knowledge creators (i.e., researchers) and knowledge users (i.e., decision-makers)[2]. It is mainly used in relation to the regulation of the health care system, quality of care, and payment for care which can have a direct effecton some economic features of the country.

In practice, HTA is the most contemporary and precise process of decision making in healthcare globally. The process is multidisciplinary, giving a different point of view and depth during the evaluation of a given health technology. At the same time every country benefits from the implementation of HTA and it has its specific internal conditions. HTA has a strong foundation in research on the health effects and broader implications of the use of technology in health care. Its potential for contributing to safer and more effective health care is widely acknowledged in Europe and interest in this field has been growing steadily. Most European Member States have established a formal HTA program. Several others are considering the feasibility of establishing official HTA process to inform health policy-making.

The development of health technology plays an essential role in promoting health and developing health systems. In recent years there appears to be increasing interest in the implementation of local authority tasks in the scope of health care in terms of healthcare programs [3].

Evaluation of the introduction and use of health technology can support decision-making addressing problems related to both equity and efficiency. This means that HTA can contribute to the allocation of scarce resources, to the selection of cost-effective health technology, to greater efficiency and more effective services, and to quality assurance in care.

HTA was developed because of rising health care costs and limited health care budgets. As HTA is of growing interest to countries outside Europe, USA, and Oceania we aim to give a prospective of the current HTA situation globally and to provide the correlation between the presence of the process and the socioeconomics fea- 
tures. The Economic evaluation of health care technologies has a key role within the National Health Service health technology assessment process. Therefore, this connection to the budget can play a major role in economic features of the country.

Most of the times researchers focus on Middle-income and Low-income countries which are often referred to as developing or emerging economies. Usually, they face multiple challenges of severe financial stress in their health care sectors and high disease burden. However, if we want to make broader conclusions on the role of HTA in the socioeconomic characteristics of the countries we have to conduct a study worldwide without focusing on specific group.

Socioeconomic status (SES) on the other hand, is consistently associated with health outcomes, yet little is known about the connection between this characteristic and the presence of HTA. In the literature is shown that SES historically has been linked to health many times and it seems that countries with higher income tend to have better organized health systems. In recent days, one of the basic points for better management of the system is the process of HTA.

\section{MATERIALS AND METHODS:}

The research was conducted via analysis of the healthcare systems in 175 countries around the world. The analyzed countries had vast social and economic differences. Health systems are complex and we tried to structure our analysis by using a conceptual framework [4]. Five criteria were used for classification regarding those differences: Population; Life expectancy at birth; Per capita total health expenditure; World Bank income group and GNI per capita.

The data about socioeconomic factors was extracted based on "information obtained from the Statistics Division and the Population Division of UN/DESA, as well as from the five United Nations regional commissions, the United Nations Conference on Trade and Development (UNCTAD), the United Nations World Tourism Organization (UNWTO), the International Monetary Fund (IMF), the World Bank, the Organization for Economic Cooperation and Development (OECD), and national and private sources." [5]

Income group information has been collected by official data published on the website of the World Bank. For the current 2016 fiscal year, low-income economies are defined as those with a GNI per capita, calculated using the World Bank Atlas method, of $\$ 1,025$ or less in 2015; lower middle-income economies are those with a GNI per capita between $\$ 1,026$ and $\$ 4,035$; upper middle-income economies are those with a GNI per capita between $\$ 4,036$ and $\$ 12,475$; high-income economies are those with a GNI per capita of $\$ 12,476$ or more. [6] The current form of the income classification has been used since 1989. It divides countries into four groups - low income, lower middle income, upper middle income, and high income - using gross national income (GNI) per capita valued annually in US dollars using a three-year average exchange rate. [7]

The limitations of the process used for gathering, processing and presentation of the data was accounted for. Verification of the data and requests for additional clarification were performed by contacting the corresponding institutions. The results were analyzed using a multi-criteria method and statistical analyzes. We then used both primary and secondary sources to collect information on the approach to HTA in each country. This was supplemented with a review of some publication regarding HTA systems in different countries all over the world.

\section{RESULTS}

Our survey covers 175 countries in total, 95 from them have not yet implemented the assessment, therefore they do not have an official HTA representative. If we turn the numbers in to percentage $-54 \%$ of all of the studied countries use HTA. These are the respondents that we examine in detail. An important part of the study is the distribution of countries according to solvency of the population. This is important socioeconomic factor which can be connected directly to HTA politics and can play major role. The result shows that $29 \%$ of all studied respondents can be categorized as high income counties, the counties with upper-middle income are approximately the samenumber. In the category of lower middle-income are included $23 \%$ of the researched countries and $19 \%$ are the counties with low income.

We separate all of the respondents (with or without HTA institution) at different regions according the group method used by United Nations - six regions (Africa, North and South America, Asia, Europe, Middle East and Oceania) and the alignment by region is represented on Fig.1. The highest percentage of the represented counties includes region Africa - 28\% followed by Europe - 24,6\%, the third are two regions with exactly the same numbers - North and South America and Asia - 17,1\%. The lowest piece is taken by Middle East $-4,6 \%$ and Oceania $-6,9 \%$.

Fig. 1. Distribution of all research countries by region.

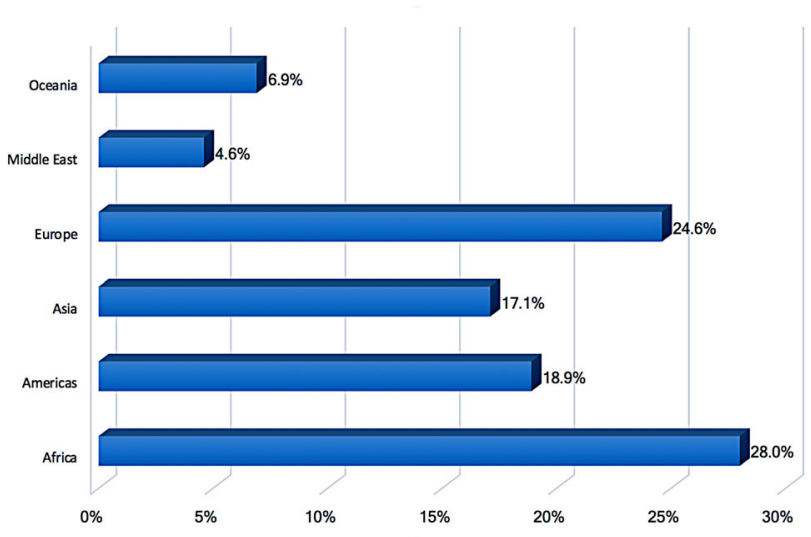


These results bring us to next figure (Fig.2) which provide detailed information about the numbers in each region of countries with or without HTA agency. The data is presented in absolute numbers, not it percentage. The conducted analyze shows that major role plays Europe as region with almost half of all agencies worldwide. Americas are presented by 14 countries that use HTA officially. Asia and Africa have the same amount of counties with official institution - 11. Middle East and Oceania are at the bottom of the table by 3-4 counties with agencies. The region with the biggest number of countries without HTA is Africa - 38 countries, followed by Asia and Americas 19. Oceania has 9 countries that are not yet using that kind of assessment and Europe has only 6.

Fig. 2. The presence or lack of HTA agencies in different regions.

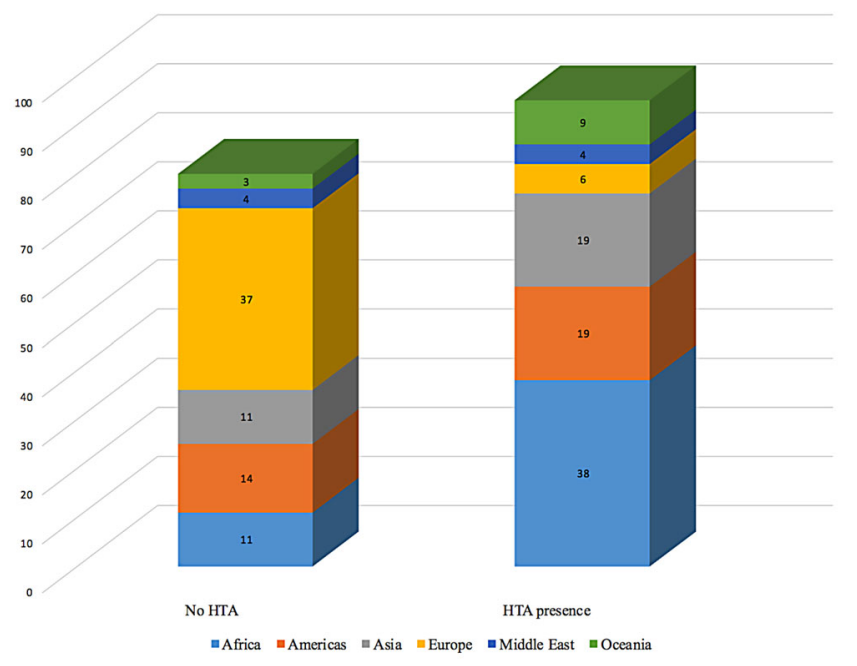

Varied statistical test was conducted in order to find the relation between the countries in different areas that use HTA process and the economic characteristic of the countries.

On the other hand, we included life expectancy at birth for statistic processing. That give us a new prospective regarding results, we find that there is a significant difference between the countries with and without HTA. Life expectancy at birth in first type of respondents is almost 8 years more than the second one. That kind of difference has to be considered by every health system as significant and can be a good point when a decision for implementation of HTA has to be taken.

In Fig. 3 we can find data about the presence or lack of HTA in countries grouped by income group. Low income countries have the lowest percentage of HTA agencies of all groups. Most of the countries with higher income have well developed HTA process which is directly connected to the economic features of the countries.
Fig. 3. The presence or lack of HTA agencies in countries grouped by income group.

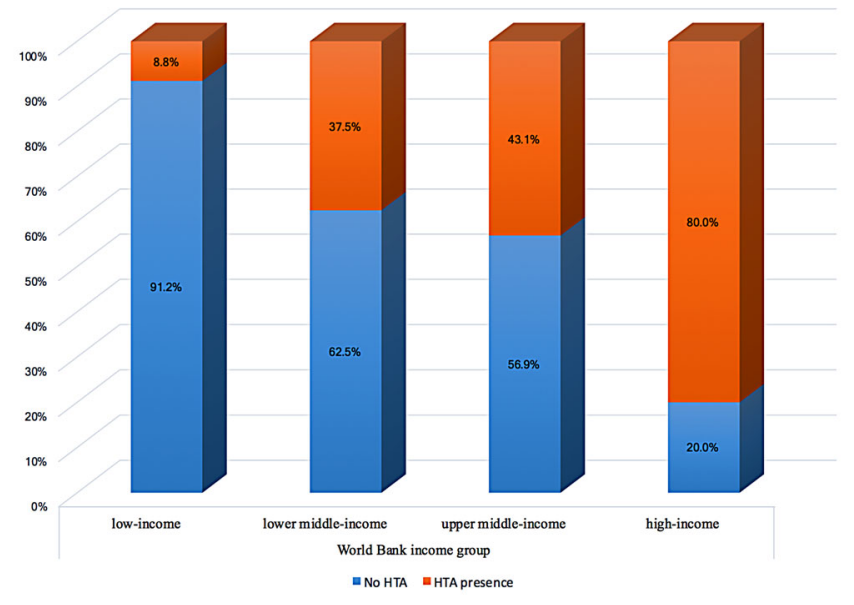

Overall the results suggest that high- and upper middle-income countries, especially in EUR and AMR, were most likely to have a formal HTA process. High-income countries were much more likely than low-income countries to use HTA for determining reimbursement or to decide what to include in the government regulated coverage scheme. Middle-income countries used HTA to inform clinical practice guidelines and protocols more often than in high- and low-income countries. Most lowincome countries and some of the middle-income countries used HTA for planning and budgeting health care activities. On the other hand, high-income countries reported using HTA not so often for this purpose.

More than half of the countries have an official HTA organization or department. That can be performed as unit or committee that produced HTA reports for the ministry of health. This was more visible in European countries than in the rest of the researched regions and they show better results in optimization of the heath budget.

\section{DISCUSSION:}

Our systematic review and research of the existing data provide a comprehensive analysis about the current situation of HTA bodies worldwide accounting the presence of official agency. We put all of the information in to statistic software in order to build a correlation model between variables.

Increased costs from running the health care system and the resulting access to modern health technology give a strong ground to HTA. The systematic identification of the scientific and social value judgments provides to better understanding of the dimensions of value, which can be used to improve their transparency and consistent use across decisions and settings [8]. However, HTA is developing with uneven speed in middle-income coun- 
tries and many countries are building on the organizational and methodological experience from established HTA agencies. This fact can bring some negative points but overall can affect positively on SES of the country.

The results show that the development of HTA correlates with GNI per capita, life expectancy at birth and World Bank income group. Further investigation need to be done including more variables in to the model.

Most of the countries with good economic indicators have an HTA agency but there are also some exceptions. There are countries with high levels of economic development, which have not yet adopted the process. There are also countries that have big populations and good social parameters, which also have not yet adopted the HTA process. Meanwhile there are also examples of the opposite, an example being a nation of 100000 people actively implementing HTA in the decision making in their healthcare system.

\section{CONCLUSION:}

Currently, HTA plays an increasingly important role in health care systems by supporting decision-making in health care policy and practice. Although HTA is most advanced in industrialized countries, there is a growing community around the world that is interested in developing and using HTA.

The question whether a country should strive to have its own HTA agency or just follow the decisions of an outside HTA agency, based in a country with similar socio-economic parameters is multi-dimensional and should be considered on a case to case basis. The organization and maintaining an HTA agency is complex and expensive in most cases. Looking beyond costs the benefits of a functioning HTA agency is indisputable and a lot of countries have undertaken the necessary steps towards this, better healthcare decision making process. The attached research shows the tendencies regarding the levels of social and economic development of the countries making steps towards establishing an HTA agency of their own. The primary objective is to identify and analyze the criteria, approaches and conceptual frameworks used for national/international priority setting [9].

In general, we can conclude that there is a correlation between HTA process and socioeconomic characteristic of the countries. HTA can play major role in the process of developing better economic features and better healthcare service. We look forward for more data according to specific details of the assessment process that can bring more light to guidance for development and building of HTA capacity.

\section{REFERENCES:}

1. Facey K, Topfer LA, Chan L. International Network of Agencies for Health Technology Assessment. Health Technology Assessment (HTA) Glossary, INAHTA Secretariat; 2006

2. Polisena J, Lavis J, Juzwishin D, McLean-Veysey P, Graham I, Harstall C, et al. Supporting the Use of Health Technology Assessments by DecisionMakers. Health Policy. 2015 May; 10(4):10-15. [PubMed]

3. Kolasa K, Turlej A, Hermanowski T. Health technology assessment of public health programs in Poland, years 2010 and 2013. Przegl Epidemiol. 2016; 70(1):77-81. [PubMed]
4. Vries G, Tsolova S, Anderson LF, Gebhard AC, Heldal E, Hollo V, et al. Health system factors influencing management of multidrug-resistant tuberculosis in four European Union countries - learning from country experiences. BMC Public Health. 2017 Apr 19; 17(1):334. [PubMed] [CrossRef]

5. United Nations, New York, Country classification, World Economic Situation and Prospects 2014, 143-150.

6. The World Bank, World Bank Country and Lending Groups, Country Classification, 2017

7. Neil Fantom, Umar Serajuddin, e World Bank's Classi cation of Coun- tries by Income, Development Economics Data Group, January 2016, Policy Research Working Paper 7528

8. Nicod E, Kanavos P. Scientific and social value judgments for orphan drugs in HTA. Int J Technol Assess Health Care. 2016 Jan;32(4):218-232. [PubMed] [CrossRef]

9. Varela-Lema L, Atienza-Merino G, Lopez-Garcia M. [Priority setting of health interventions. Review of criteria, approaches and role of assessment agencies]. [in Spanish] Gac Sanit. 2017 JulAug;31(4):349-357. [PubMed] [CrossRef]

Please cite this article as: Georgiev S, Yanakieva A, Priftis S. Socioeconomic characteristics of countries based on the presence of HTA agency. J of IMAB. 2017 Jul-Sep;23(3):1637-1640. DOI: https://doi.org/10.5272/jimab.2017233.1637

\author{
Address for correspondence: \\ Svetlin G. Georgiev, \\ Department of Health Technology Assessment, Faculty of Public Health, Medical \\ University - Sofia \\ 146B, Vitosha Blvd., Office 16; 1463 Sofia, Bulgaria \\ E-mail: svetlinggeorgiev@gmail.com
}

